\section{Avaliação endoscópica das lesões nas vias aéreas superiores decorrentes da intubação endotraqueal em cães}

\author{
Endoscopic evaluation of upper airway lesions due to \\ endotracheal intubation in dogs
}

\author{
Luciana de Oliveira DOMINGOS ${ }^{1}$; Ângelo João STOPIGLIA²; Valéria Pires CORRÊA²; Denise \\ Tabacchi FANTONI ${ }^{2}$
}

CORRESPONDENCE TO Ângelo João Stopiglia Departamento de Cirurgia Faculdade de Medicina Veterinária e Zootecnia da USP Av. Prof. Dr. Orlando Marques de Paiva, 87 - Cidade Universitária Armando de Salles Oliveira 05508-000 - São Paulo - SP Brasil e-mail: stopa@usp.br

1 - Hospital Veterinário Faculdade de Medicina Veterinária e Zootecnia da USP 2 - Departamento de Cirurgia

Faculdade de Medicina Veterinária e Zootecnia da USP

\title{
RESUMO
}

Avaliou-se, por exame endoscópico sob anestesia geral, em 15 cães, as lesões decorrentes da intubação endotraqueal nas vias aéreas superiores e na traquéia, após 90 minutos e decorridas 24 horas deste procedimento. Nos cinco animais em que o balonete da sonda foi inflado com 100 mmHg observou-se, após 90 minutos, 20\% de hiperemia e $80 \%$ dos cães sem lesão; após 24 horas da extubação não se constatou nenhum tipo de lesão nesses animais; no grupo em que foi imprimida pressão de $150 \mathrm{mmHg}$ constatou-se $20 \%$ de hiperemia aos 90 minutos e nenhuma anormalidade após 24 horas; nos cinco cães em que se inflou o balonete da sonda com pressão aleatória, às cegas, e posteriormente medida, encontrou-se $40 \%$ de hiperemia, 20\% de hematoma, 20\% de ulceração e $20 \%$ de escoriação, após 90 minutos de intubação, e $40 \%$ de hematoma, $40 \%$ de ulceração e $20 \%$ de escoriação, 24 horas depois do primeiro exame endoscópico. Concluiu-se que pressões acima de $180 \mathrm{mmHg}$, por 90 minutos, causaram lesão persistente na traquéia, até 24 horas após a extubação, e a região acometida foi aquela em que se posicionou o balonete da sonda endotraqueal.

\section{UNITERMOS: Endoscopia; Cães; Traquéia; Lesões; Intubação endotraqueal.}

\section{INTRODUÇÃO E LITERATURA}

A intubação endotraqueal em cães, prática rotineira em procedimentos cirúrgicos, é importante para assegurar a passagem do ar aos pulmões, prevenir aspiração de conteúdo estomacal ou líquidos, permitir ventilação eficaz, facilitar a administração de oxigênio e drogas anestésicas por inalação (Hall: Clarke $\left.^{1(t}, 1983\right)$. Entrementes, podem ocorrer, entre outras complicações, contaminação bacteriana do trato respiratório, hemorragias e lesões da mucosa traqueal ou ainda obstrução respiratória pela compressão da sonda contra o lúmen traqueal, decorrentes da pressão elevada do balonete do tubo endotraqueal (Auler Jr. et al.', 1992).

Poucas foram as informações coligidas sobre o assunto em cães (Brent ${ }^{3}, 1990$ ), e a maioria dos trabalhos foram realizados na espécie humana.

No que tange aos eqüinos, foram descritos hematoma laringiano na epiglote e aritnóide, quando utilizada sonda sem balonete, e perfuração faringiana em um potro, fatos constatados

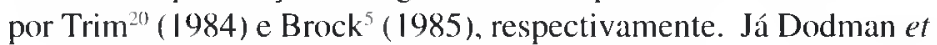
al. (1986) observaram, por exame radiográfico da faringe, a retroversão da epiglote como complicação à intubação endotraqueal. Heath $e t$ al. ${ }^{11}$ (1989) observaram lesões na laringe e traquéia associadas à intubação, através de endoscopia realizada imediatamente e 24 horas após a retirada do tubo endotraqueal.

No que se refere aos cães, foi registrada estenose traqueal em virtude da intubação endotraqueal, traduzida por tosse, dispnéia e cianose, além do epitélio deste órgão ter sido substituído por tecido conjuntivo fibroso (Knecht et al. ${ }^{15}, 1972$ ). O mesmo referiram
Suter et al..$^{17}$ (1972), além de pregas nos ligamentos anulares e lesão de integridade ciliar. Esta última lesão, com áreas de destruição ciliar e modificações no tamanho e forma da mucosa traqueal, foi observada por Klainer et al. ${ }^{14}$ (1975), após duas horas de intubação endotraqueal. Já Hill ${ }^{13}$ ( 1974) informou sobre lacerações ou rupturas traqueais motivadas pelo balonete da sonda endotraqueal, excessivamente inflado, promovendo hemoptise, pregas nos ligamentos anulares e fratura das cartilagens traqueais.

Ainda na espécie canina, Bojrab; Renegar ${ }^{4}$ (1981) afirmam que a isquemia da mucosa traqueal é causada pela pressão no balonete do tubo endotraqueal e, quanto maior for a pressão ou o tempo em que o balonete permanecer inflado, mais grave será a lesão provocada, recomendando que se atente ao grau de pressão imprimido e o tempo em que o balonete ficará pressionando a parede traqueal. Finalmente, Ettinger; $\operatorname{Ticer}^{7}$ (1989) relataram o caso do cão da raça Dinamarquês, fêmea, com três meses de idade, que apresentou angústia respiratória, dois dias após a intubação endotraqueal, com laceração da mucosa traqueal, obstrução por prega e hipoplasia constatadas por exame radiológico.

Cumpre assinalar que estenose traqueal congênita, comum em humanos, na infância, é rara em cães (Suter et $a l .{ }^{17}, 1972$ ), sendo relatada a estenose subglótica congênita nessa espécie (VenkerVan Haagen et al. ${ }^{21}$, 1981). Por fim, Hedlund ${ }^{12}$ (1987) e Tams ${ }^{18}$ (1990) observaram diferentes tipos de lesões sediados no trato respiratório superior, através de exame endoscópico.

Assim, em face das escassas informações de literatura, encetou-se o estudo com o fito de evidenciar, através do exame endoscópico, possíveis lesões que o tubo endotraqueal causaria nas 
vias aéreas superiores de cães, quando submetidos à intubação endotraqueal, dando prosseguimento à linha de trabalho desenvolvida com a mesma finalidade em eqüinos (Freitas et $a l .^{8}, 1994$ ).

\section{MATERIAL E MÉTODO}

Utilizaram-se 15 cães, machos ou fềmeas, com faixa etária estimada em jovem e adulta, sem raça definida e provenientes do Canil Central da Faculdade de Medicina Veterinária e Zootecnia da USP.

Esses animais, após exame clínico e anestesia barbitúrica de curta duração, foram submetidos a exame endoscópico prévio para eliminar a presença de lesão. Em seguida, procedeu-se à intubação endotraqueal com sonda de Magill, realizada pela mesma pessoa, pelo período padronizado de 90 minutos. A anestesia constou de acepromazina*, por via intravenosa na dose de $0,1 \mathrm{mg} / \mathrm{kg}$, indução com tiopental sódico** a $2,5 \%$ na dose de $12,5 \mathrm{mg} / \mathrm{kg}$, pela mesma via, e manutenção pelo halotano ${ }^{* * *}$ diluído em oxigênio, em sistema fechado do aparelho de anestesia ${ }^{* * *}$, o suficiente para manter o animal no $3^{\circ}$ plano de anestesia do III estágio em respiração espontânea (Guedel", 1952).

Dividiram-se os animais em três grupos de cinco cães, assim distribuídos: no grupo I, os animais tiveram o balonete da sonda inflado sem medição imediata da pressão no interior deste, insuflado às cegas, e posteriormente essas pressões foram tomadas e anotadas; no grupo II, aplicou-se pressão de $100 \mathrm{mmHg}$ no balonete de sonda; e no grupo III, pressão de $150 \mathrm{mmHg}$. Utilizou-se esfigmomanômetro****** para a tomada da pressão.

Foram registrados os dados referentes a sexo, peso, faixa etária, número de tentativas para a intubação do animal e o diâmetro da sonda utilizada.

Os exames endoscópicos realizados, sob anestesia. logo após a extubação, isto é, decorridos 90 minutos da intubação, e após 24 horas, avaliaram as seguintes lesões quanto ao tipo e ao grau das vias aéreas superiores e traquéia: animais sem lesão; com lesão leve - hiperemia,,-++++++ ; com lesão moderada - hematoma,-+++ , +++ ; com lesão grave - ulceração; e, ainda, hemorragia, presença de fibrina e escoriações leves $(+)$, moderadas $(++)$ e graves $(+++)$.

Utilizou-se endoscópio flexível de fibras ópticas ${ }^{* * * * * *}$ e fonte de luz da Micronal ${ }^{1 * * * * * *}$, a fim de que os campos de interesse fossem fotografados.

Relacionou-se a presença de lesão com a pressão utilizada no balonete da sonda, além dos dados referentes a sexo, faixa etária, peso, diâmetro da sonda e número de vezes necessárias para a intubação do animal.

\section{RESULTADOS}

Os dados relativos a sexo, peso e faixa etária encontram-se discriminados nas Tabs. I, 2, 3, bem como o número de tentativas, que variou de uma a duas vezes, para se conseguir intubar os ani-

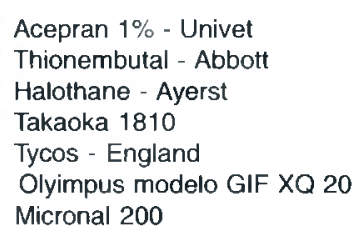

mais, e o diâmetro interno das sondas utilizadas. Outrossim, as lesões estão relacionadas nas mesmas Tabs., segundo o tipo e o grau.

Nos animais do grupo I, as lesões mostraram-se presentes em todos os animais, logo após a extubação, persistindo os hematomas, as ulcerações e as escoriações, decorridas 24 horas do primeiro exame.

Já as hiperemias observadas nos cães dos grupos II e III desapareceram nesse período de tempo, diferente da hiperemia $(++)$ observada no grupo I que se transformou em hematoma.

Apenas se poderá correlacionar tipo e grau de lesão com a pressão exercida no balonete da sonda endotraqueal quando houver relação com os demais parâmetros analisados.

Observaram-se nos cães do grupo 1, após a extubação. hiperemia (independente do grau) em 2 animais (40\%): hematoma em I animal (20\%); ulceração em I animal (20\%) c escoriação em apenas 1 animal $(20 \%)$.

No grupo II, observou-se hiperemia em uma oportunidade $(20 \%)$, não sendo observado qualquer tipo de lesão nos demais animais $(80 \%)$. Em relação ao grupo III, nada foi constatado em quatro animais $(80 \%)$, enquanto apenas um apresentou hiperemia $(20 \%)$. $\mathrm{O}$ aparecimento das lesões restringiu-se à região da traquéia correspondente ao local de pressão do balonete da sonda.

Após 24 horas de extubação, constatou-se no grupo I: hematomas em 2 animais (40\%), ulceração em outros dois (40\%) e escoriação em apenas um deles $(20 \%)$. Nos quadros de ulceração e escoriação constatou-se a presença de fïbrina no local das lesões. Nos grupos II e III, nenhuma lesão foi observada decorridas 24 horas da extubação.

\section{DISCUSS̃̃O}

Pelos dados obtidos nos animais dos três grupos, não se pode correlacionar o número de tentativas para a intubação e a ocorrência de lesões, à semelhança do observado por Heath et al. " (1989). A faixa etária estimada (jovens e adultos) também não foi fator determinante no aparecimento ou não de lesões após a sondagem endotraqueal. Apuraram-se lesões de diferentes lipos e diversos graus, em jovens e adultos.

Quanto ao fator pressão, Nordin ${ }^{16}$ ( 1977) cita que, para os seres humanos, a aplicação maior de $50 \mathrm{mmHg}$, por 15 minutos, destrói o epitélio, deixando a membrana basal exposta. Cita, ainda, lesão do tipo isquêmica em traquéia, quando a pressão do balonete na parede deste órgão excede a pressão de perfusão capiłar (20) a 30 $\mathrm{mmHg}$ ). Assim, para Bernhard et al..$^{2}$ ( 1979 ), pressões de $18 \mathrm{mmlyg}$ já seriam suficientes para prevenir a aspiração de todo o material líquido. Embora não se tivessem realizado exames histopalológicos da região da traquéia pressionada pelo balonete, julga-se que os dados levantados, pelos aludidos autores, para o homem não podem ser transportados diretamente para a espécie canina. Assim, com base nos nossos dados, pode-se constatar, em um animal, hiperemia leve com 100 ou $150 \mathrm{mmHg}$, enquanto pressões aleatórias, acima de $180 \mathrm{mmHg}$, provocam algum tipo de lesão em lodos os cães, em diversos graus. Desta forma, novos estudos devem ser orientados no sentido de se avaliar qual a pressão mínima que conseguiria prevenir a aspiração de material líquido e, ao mesmo tempo, evitar a lesão na parede traqueal, correlacionando esses dados com o tempo mínimo necessário para o aparecimento das referidas lesões, como pôde constatar Nordin ${ }^{16}$ ( 1977). 
Comprovaram-se, neste estudo, hiperemias, hematomas, ulcerações e escoriações (Figs. I e 2), inclusive com presença de hemorragia e fibrina, à semelhança do verificado por Freitas et $a l^{8}$ (1994) em equiinos. mas jamais se observou estenose traqueal em cães, como relataram Knecht et al. ${ }^{15}$ (1972) e frisaram Tangner; Hedlund ${ }^{19}$ (1983). Da mesma forma, não se constataram lacerações ou rupturas tracueais, como descreveu Hill'3 (1974), tampouco hipoplasia traqueal, observada por Klainer et al. ${ }^{14}$ ( 1975 ) e Ettinger; Ticer $^{7}$ (1989).

Da mesma maneira que se constataram desde hiperemias leves até ulcerações hemorrágicas e escoriações com deposição de fïbrina. Bojrab; Renegar (1981) descreveram lesões traqueais que variaram desde edema e ulceração superficial até necrose isquêmica com tecido de granulação. Tais autores afirmaram que a pressão imprimida no balonete e o tempo de permanência pressionando a traquéia são os causadores de lesão da mucosa. Comprovadamente, o animal que recebeu maior pressão no interior do balonete (380 $\mathrm{mmHg}$ ) foi aquele que apresentou lesão mais severa quando comparado com os outros cães. Quanto ao tempo de permanência, nada se tem a relatar, haja vista os 90 minutos uniformes em todos os animais do experimento, independente do grupo. Contudo se admite como factível a opinião exarada por Bojrab; Renegar' (1981) de que, para se reduzir a possibilidade de lesionar a mucosa traqueal, deve-se estar atento ao grau de pressão imprimida no balonete da sonda.

Finalmente, julga-se que novos trabalhos devam ser encetados, com a finalidade de analisar, principalmente, qual a pressão mínima no balonete e o tempo mínimo de permanência da sonda endotraqueal que permitam o aparecimento de lesões traqueais em animais da espécie canina.

\section{CONCLUSÕES}

1) O aparecimento de lesões traqueais em cães está diretamente relacionado com a pressão exercida pelo balonete da sonda endotraqueal;

2) Pressões superiores a $180 \mathrm{mmHg}$, por 90 minutos, no balonete da sonda causam persistência de lesões traqueais até 24 horas após a extubação;

3) A intubação endotraqueal pode vir a causar desde hiperemias leves e hematomas até ulceraçôes e escoriações na traquéia;

4) A região da traquéia onde se posiciona o balonete da sonda endotraqueal é o ponto de eleição para o aparecimento de lesões.

\section{Lesões observadas logo após a extubação}

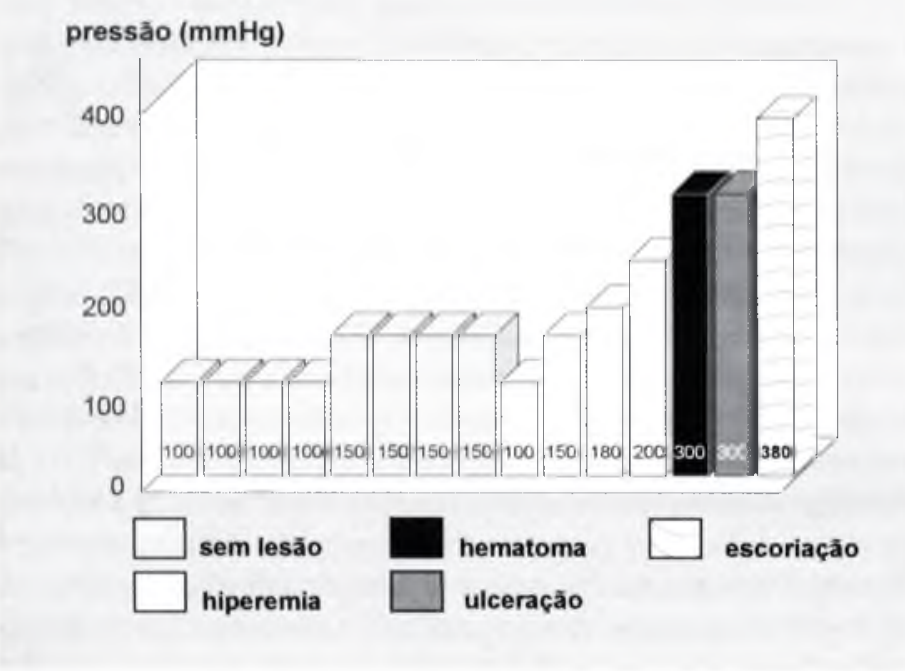

Figura 1

Histograma relacionando lesões observadas à pressão do balonete da sonda endotraqueal, nos 15 cães analisados.

\section{Lesões observadas 24 horas após a extubação}

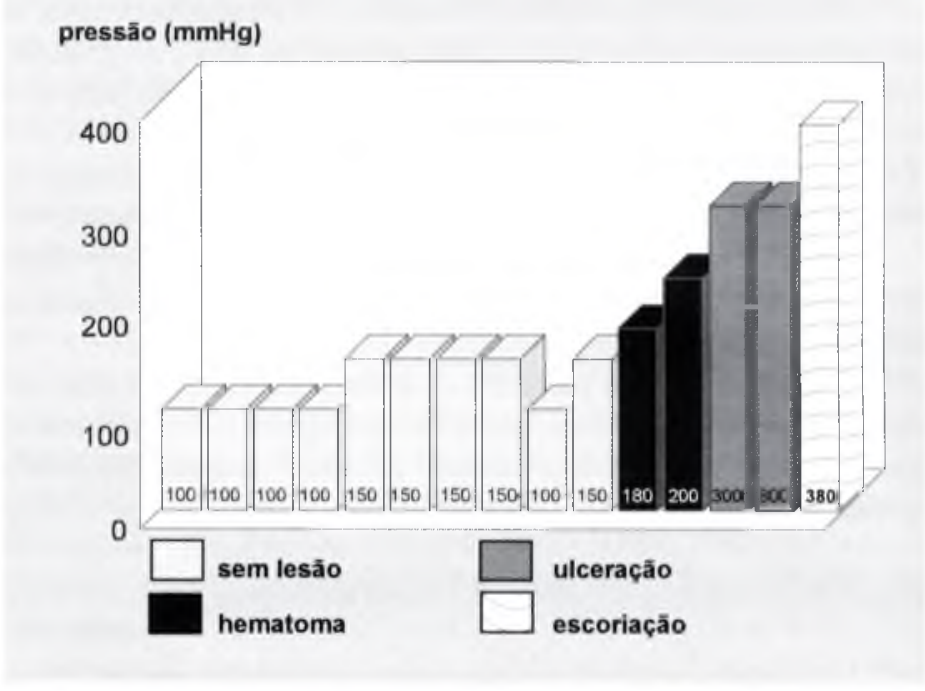

Figura 2

Histograma relacionando lesões observadas à pressão do balonete da sonda endotraqueal, nos 15 cães analisados. 
Tabela 1

Dados referentes aos animais do Grupo I. Pressão aleatória no balonete da sonda endotraqueal.

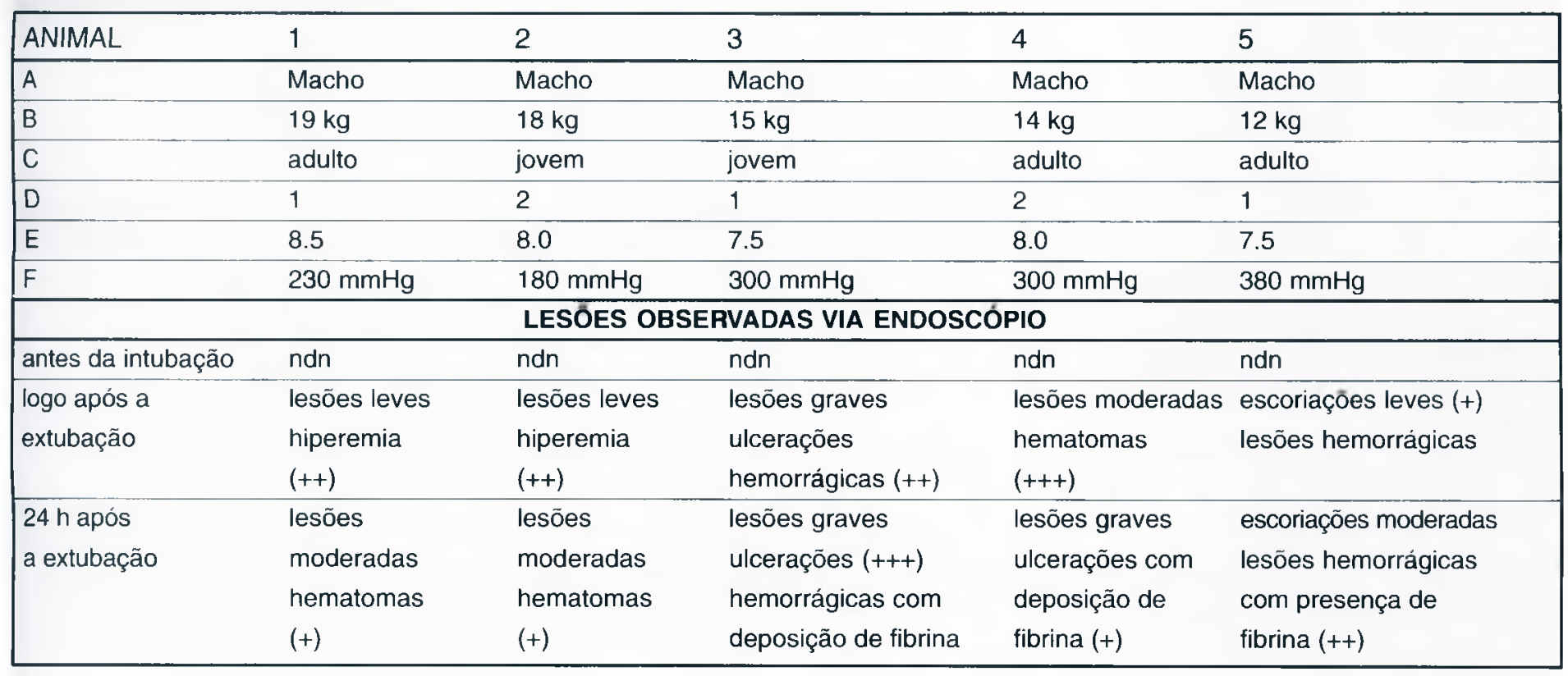

$\mathrm{A}=$ Sexo; $\mathrm{B}=$ Peso; $\mathrm{C}=$ Faixa etária estimada; $\mathrm{D}=$ № de tentativas de intubação; $\mathrm{E}=$ № da sonda endotraqueal;

$\mathrm{F}=$ Pressão do "cuff" da sonda endotraqueal; ndn = nada digno de nota.

Tabela 2

Dados referentes aos animais do Grupo II. Pressão de $100 \mathrm{mmHg}$ no balonete da sonda endotraqueal.

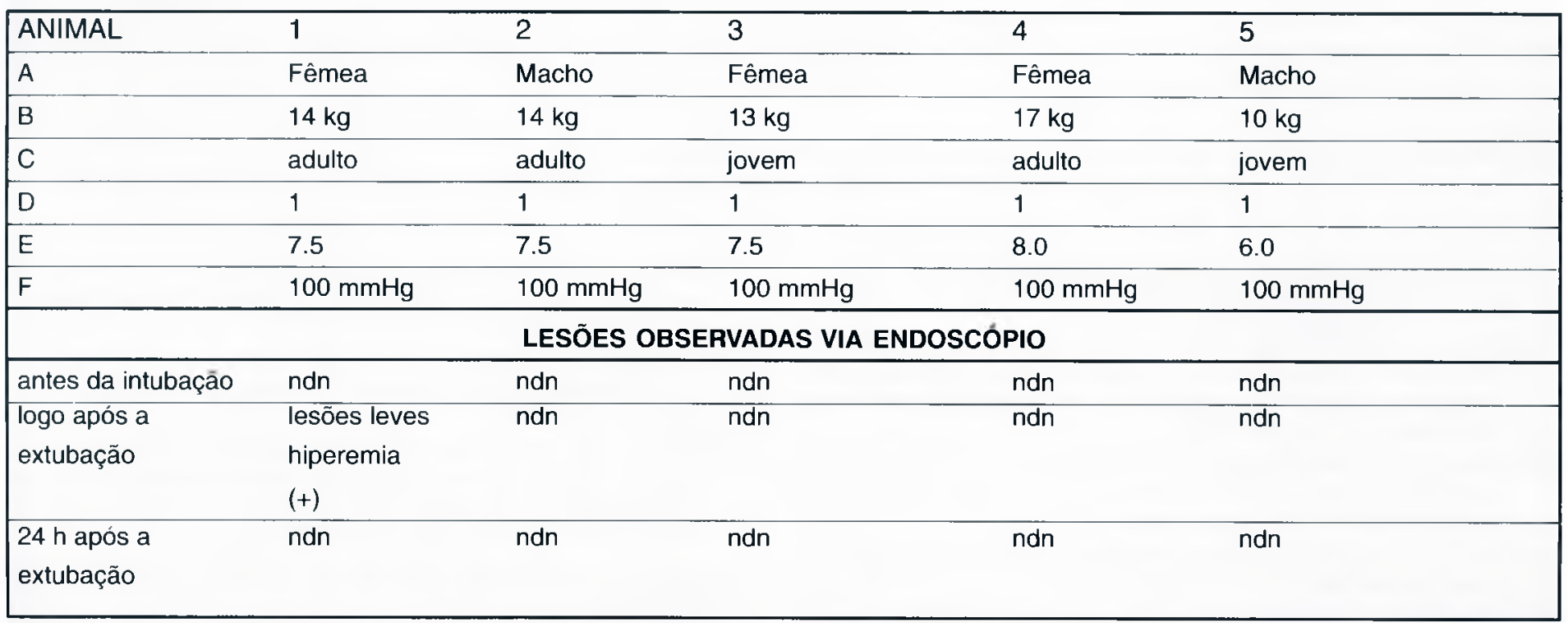

$A=$ Sexo; $B=$ Peso; $C$ = Faixa etária estimada; $D=N^{\circ}$ de tentativas de intubação; $E=$ № da sonda endotraqueal;

$F=$ Pressão do "cuff" da sonda endotraqueal; ndn = nada digno de nota. 


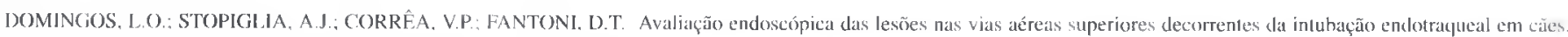
Braz. J. vet. Res. anim. Sci., São Paulo, v. 34, n. 5. p. 278-283. $199 \%$

Tabela 3

Dados referentes aos animais do Grupo III. Pressão de $150 \mathrm{mmHg}$ no balonete da sonda endotraqueal.

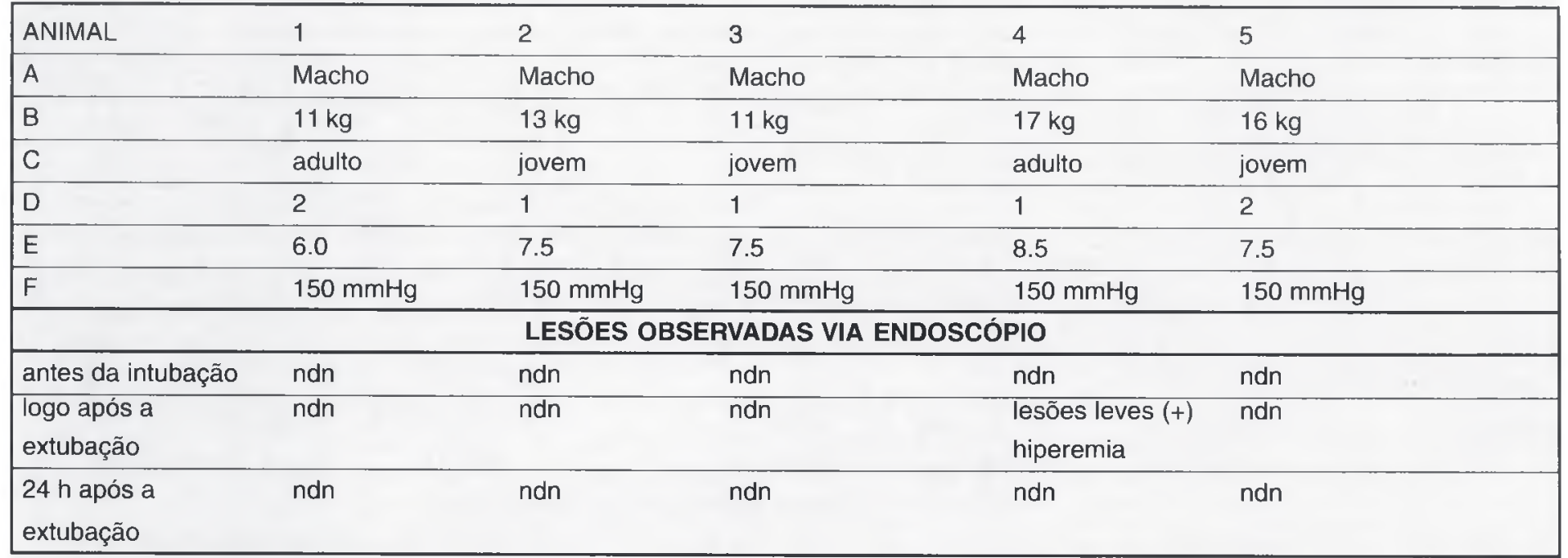

$\mathrm{A}=$ Sexo; $\mathrm{B}=$ Peso; $\mathrm{C}=$ Faixa etária estimada; $\mathrm{D}=$ № de tentativas de intubação; $\mathrm{E}=$ № da sonda endotraqueal;

$\mathrm{F}=$ Pressão do "cuff" da sonda endotraqueal; $\mathrm{ndn}=$ nada digno de nota.

\section{SUMMARY}

It was evaluated, by endoscopy and using general anesthesia, the upper airway and trachea lesions due to endotracheal intubation after 90 minutes and after 24 hours of the procedure, in 15 dogs. In five animals submitted to cuff pressure of $100 \mathrm{mmHg}$, it was observed, after 90 minutes, $20 \%$ of hyperemia; $80 \%$ of the dogs presented no lesion. Twenty-four hours after extubation, it was not found any kind of lesion in all the animals. In the group submitted to a cuff pressure of $150 \mathrm{mmHg}$, it was verified hyperemia in $20 \%$ of the animals after 90 minutes of endotracheal intubation and no abnormality after 24 hours. The third group was submitted to cuff inflated with a random pressure, which was measured afterwards. In this group, it was found $40 \%$ of hyperemia, $20 \%$ of hematoma, $40 \%$ of ulceration and $20 \%$ of laceration, 24 hours after the first endoscopic exam. It could be concluded that pressures above $180 \mathrm{mmHg}$ for 90 minutes cause persistent tracheal lesion, as late as 24 hours after the extubation; lesion site frequently was exactly the cuff location.

UNITERMS: Endoscopy; Dogs; Trachea; Lesions; Endotracheal intubation.

\section{REFERÊNCIAS BIBLIOGRÁFICAS}

I- AULER JR. . J, O. C.: FEITRIM. M. I. Z.: FERREIRA. C. A. S.; OL IVEIRA, C Avaliação da pressão do balão do tubo endolraqueal nas primeiras horas do pós-operatório imediato de cirurgia cardíaca. Revista Brasileira de Terapia Intensiva, v.4, n.4, p.116-9. 1992.

2-BERNHARD, W. N ; COTTRELL, J.E.; SIVAKUMARAN, C.; PATEL, K.; YOST I..; TURNDORF, H. Adjustment of intracuff presure to prevent aspiration. Anesthesiology, n. 5, v.4, p.36.3-6, 1979.

3- BRENT, D. J. Veterinary endoscopy. Veterinary Clinics of North America Small Animal Practice, v.20, n. 5, p. 213, 1990.

4- BOJRAB, M. J.; RENEGAR, W. R. The trachea. In: BOJRAB, J. (ed.) Pathophysiology in Small Animal Surgery. Philadelphia, L.ea \& Febiger, 1981, p. 366

5- BROCK, K. A. Pharingeal trauma from endotracheal intubation in a colt. Journal of American Veterinary Medical Association, v. 187, n.9, p.944-6, 1985
6- DODMAN, N. H.; KOBLIK, P. D.; COURT, M. H. Retroversion of the epiglott is as a complication of endotracheal intubation in the horsc. Veterinary Surgery. v. 15, n..3, p.275-8, 1986.

7 - ETTINGER, S. J.; TICER, J. W. Diseases of the 1rachea. In ETTINGER, S. I. (ed.) Textbook of veterinary internal medicine. 3. ed. Philadelphia, W B. Saunders, 1989. p.853

8 - FREITAS, R. R ; STOPIGLIA, A. J.: FANTONI, D. T.; SIIVA. I. C. L. C Lesões das vias aéreas superiores após intubação endotracjueal em equïinos. In: CONGRESSO BRASILEIRO DE CIRURGIA E ANESTESIOLOGIA VETERINÁRIA. Curitiba. PR, 1994. Anais. p.4I

9 - GUEDEL, A. E. Inhalation anesthesia. 2.ed. New York, Macmilliam, 1952. p. 347 .

10- HALL. L. W.; CLARKE, K. W. Veterinary anaesthesia. 8. ed. London, Bailliere Tindall, 1983. $417 \mathrm{p}$

II-HEATH R. B.; STEFFEY, E. P.; THURMON, J. C ; WERTZ, E. M.; MEAGHER. D.M.: HYYPPA, T.; Van SLYKE, G.L. Laringotracheal lesions following 
DOMINGOS, L.O.; STOPIGLIA, A.J.; CORRÊA, V.P.; FANTONI, D.T Avaliação endoscópica das lesōes nas vias aéreas superiores decorrentes da intubação endotraqueal em cães. B raz. J. vet. Res. anim. Sci., São Paulo, v. 34, n. 5, p. 278-283, 1997.

routine orotracheal intubation in the horse. Equine Veterinary Journal, v.21, n.6, p.434-7, 1989

12 - HEDLUND, C. S. Surgical diseases of the trachea. Veterinary Clinics of North America Small Animal Practice. v.17, n.2. p.30 . 1987.

13 - HILL, F. W. G. Repair of a traumatic rupture in the trachea of a dog. Veterinary Record. v.95, n. 12, p.265-6, 1974.

14 - KLAINER, A. S.; URNDORF, H.; AKWAL, H.: ALLANDER, P. Surface alterations due to endotracheal intubation. American Journal of Medicine, v. 4, n.58, p.674-83, 1975.

15 - KNECHT , C. D.; SCHALI, W. D.; BARRET, R. Iatrogenic tracheostenosis in a dog. Journal of the American Veterinary Medical Association, v. 160, n.10, p.1427-9, 1972.

16 - NORDIN, U. The trachea and cufl - induced tracheal injury. Acta Otolaryngologia (Stockh), v.7, p.7-69, 1977. Supplement 345.
17 - SUTER , P. F.; COLGROVE, D. J.; EWING, G. O. Congenital hipoplasia of the canine trachea. Journal of the American Animal Hospital Association, v.8, n. 2 , p. $120,1972$.

18 - TAMS, T. R. Endoscopy of the lower respiratory tract of the dog and cal. Small Animal Fndoscopy. Missouri, Mosby, 1990. p.309-14.

19 - TANGNER, C. H.; HEDLUND, C. S. Tracheal surgery in the dog - part I. Compendium on Continuing Fducation for the Practicing Veterinarian. v.5, n.8, p. $599-606,1983$

20- TRIM, C. M. Complications associated with the use of the cuflless endotraqueal lube in the horse. Journal of the American Veterinary Medical Association. v.185, n.5, p.541-2, 1984.

21 - VENKER-VAN HAAGEN, A. J.; ENGELSE, E. J. J; VAN DEN INGH, S. G. Congenital subglotic stenosis in a dog. Journal of the American Animal Hospital Association, v. 17, n. 2, p.223, 1981 